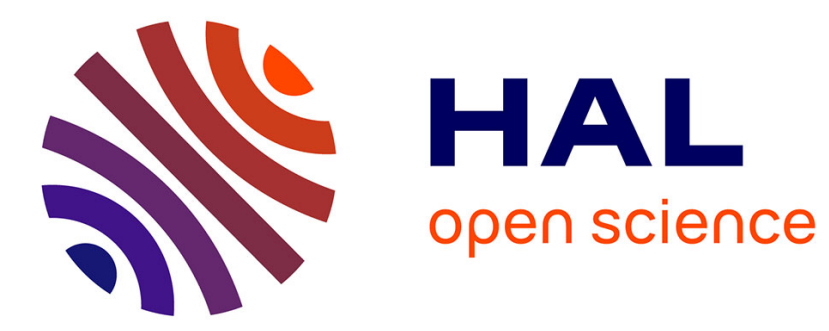

\title{
Stochastic simulations and stability to determine maximum wind power penetration of an island network
}

Wendy Carolina Briceño Vicente, Raphaël Caire, Nouredine Hadjsaid

\section{To cite this version:}

Wendy Carolina Briceño Vicente, Raphaël Caire, Nouredine Hadjsaid. Stochastic simulations and stability to determine maximum wind power penetration of an island network. 2017 IEEE Power \& Energy Society General Meeting (PESGM), Jul 2017, Chicago, United States. 10.1109/PESGM.2017.8273855 . hal-01809938

\section{HAL Id: hal-01809938 \\ https://hal.science/hal-01809938}

Submitted on 7 Jun 2018

HAL is a multi-disciplinary open access archive for the deposit and dissemination of scientific research documents, whether they are published or not. The documents may come from teaching and research institutions in France or abroad, or from public or private research centers.
L'archive ouverte pluridisciplinaire HAL, est destinée au dépôt et à la diffusion de documents scientifiques de niveau recherche, publiés ou non, émanant des établissements d'enseignement et de recherche français ou étrangers, des laboratoires publics ou privés. 


\title{
Stochastic simulations and stability to determine maximum wind power penetration of an island network
}

\author{
W. C. Briceno Vicente, R. Caire Member, IEEE, N. Hadjsaid Fellow, IEEE
}

\begin{abstract}
Wind power is the fastest developing renewable energy source in power networks. The maximization of wind power penetration depends on constraints imposed by network topology, electrical and mechanical limits, temporal variations of wind power injections and load consumption. In order to determine the maximum wind power penetration, uncertainties must be considered. The proposed method uses stability criterion (time domain simulations and) mixed with stochastic simulation, under different contingency scenarios. It determines the Probability Density Function (PDF) of unstable cases using small signal stability according to wind power penetration. The study case was IEEE 9-bus transmission network and two contingencies were considered: three phases short-circuit for Fault Ride Through (FRT) capability, and loss of a generation unit. The loss of a machine is the worst limiting operational condition which determines wind power penetration of the network within the operational limits of wind turbines (WTs).

Index Terms--Eigenvalue analysis, grid code requirements, maximum wind power penetration, Monte-Carlo Simulation (MCS), Probability Density Function (PDF), small-signal stability, time domain simulation, uncertainty, Wind Turbine (WT).
\end{abstract}

\section{INTRODUCTION}

$\mathrm{P}$ ower networks are changing from a vertical operated structure, built-up around large conventional power plants, to more horizontal structures with connection of new loads and power sources. The integration of Renewable Energy Sources (RES) creates new technical problems during the planning studies such as: voltage and power variations, increase of short-circuit levels [1-2], harmonics coming from converters [3], flicker that affects power quality [4], possible resonances and instability issues. Wind power takes advantage of wind speed which is highly unpredictable (as a result of changes in weather conditions). Therefore, large wind power generation affects dynamic operation of power network; which has motivated the development of widely applicable studies and contingency analysis considering uncertainties to evaluate its impact in stability. In addition to

This work was supported by the G2Elab, Grenoble INP, Grenoble, 38031; France. W. C. Briceño Vicente is now with Siemens Wind Power, R. Caire and N. Hadjsaid are with the G2Elab, Grenoble, 38031; France. (e-mails: wendy.briceno@siemens.com, raphael.caire@g2elab.grenoble-inp.fr, nouredine.hadjsaid@g2elab.grenoble-inpg.fr,). variations of wind power injection, other electrical parameters are constantly fluctuating, and affect the network stability, such as load consumption which is highly unpredictable despite the advances in forecasting methods.

In recent years, probabilistic approaches have been used to evaluate the stability and reserve requirements of power networks with large amount of RES. The impact of stochastic uncertainty of WTs connected into the grid has been investigated using small-signal stability studies under an analytical probabilistic approach in [5]. In addition, other probabilistic assessment method has been proposed based on Eigenvalue analysis and numerical probabilistic approach to evaluate the impact of wind power in dynamics [6], and steady-state voltage stability analysis in [7-8]. The maximum wind power penetration using fixed-speed WT technology in island network has been determined using a different methodology of the Dynamic Maximum Available Power (DMAP) [9]. Probabilistic methodologies are applied in [10] to evaluate the reserve requirements of power systems with a large penetration of RES.

This paper proposes a methodology that focuses on transient stability of an island transmission network, where a large amount of wind power is produced. Two contingencies are studied in the dynamic simulation; these are a three phase short-circuit fault and the loss of a generation unit that affects the topology, and may cause the disconnection of other components. Additionally, other constraints such as bus voltage limitations, thermal line limits, synchronous machine loading capability, and WT grid code requirements influence the network dynamic behavior.

Load variation and wind speed are source of uncertainty and of perturbation during simulation. A probabilistic model of load variations is built from annual load measurements, while wind speed variations are modeled according to Mexican hat wavelet curve described in IEC 61400-1 [11]. A random sampling of load probabilistic model is executed during the dynamic simulation based on the Monte-Carlo simulation method, which can be used to determine the PDF of unstable network cases. The dynamic simulation and small signal stability analysis of the network are run in Matlab using Power Systems Toolbox (PSAT) [12].

The proposed methodology determines the maximal wind 
power penetration according to network limitations and stability considering load uncertainty and wind speed variations; it can be applied to planning studies of transmission networks with an important wind power penetration. The method is tested in IEEE 9 bus test case which represents a portion of the Western System Coordinating Council (WSCC) transmission network. The WSCC is composed by 9-bus, 3-generators and 3-loads. It is considered the interconnection of a large wind farm composed by Doubly-Fed Induction Generator (DFIG) WT units of 2.0 MW. The WSCC network is comparable to Guadalupe Island transmission network due to its ring topology. The Irish grid code requirements for WT are considered in the study case.

\section{DEFINITIONS}

\section{A. Power System Stability}

The power system stability may be defined as the property of a power system to remain in a state of operating equilibrium, under normal operating conditions or after being subjected to a disturbance and to regain an acceptable state of equilibrium [13]. From this general definition, stability can be classified in several categories and subcategories in figure 1.

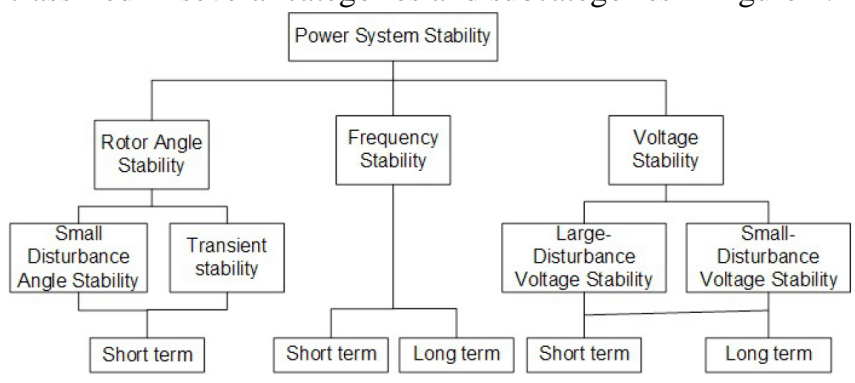

Fig. 1. Classification of power system stability

In transient stability (rotor angle stability) synchronous machines must keep synchronism after a severe disturbance (single or multiphase short-circuit or a generator loss). While in small-signal stability, the disturbance is sufficiently small that the system response is linearized.

In the case of frequency stability, the power system faces active power deficit that can be compensated with energy stored in rotating masses of all generators, increasing the power generation of primary or secondary controlled units or with a re-dispatch of power generation.

In voltage stability, the power system must maintain steady voltages after being subjected to small disturbances, such as increasing load, change in solar PV output; or following large disturbances, as transmission line trip.

Other method to analyze dynamics and stability is by timedomain simulation which is a state space representation of the system. The system state and outputs are determined by inputs, state variables, and differential equations that describe the system dynamics.

\section{B. Dynamic simulations}

The power network solution is found by a temporal timestep computation of load-flow. The dynamic behavior of the power network is modeled with a set of nonlinear ordinary differential equations [13].

$$
\begin{aligned}
& x=f(x, u) \\
& y=g(x, u)
\end{aligned}
$$

where $x, u$ and $y$ are the system's state variables, inputs and outputs respectively. The time domain simulation allows observing the evolution of electrical variables during the simulation time, considering changes of network topology or disturbances. The solution is found by an integration method, such as: forward Euler or trapezoidal rule.

\section{Small-signal stability}

If the derivatives of the state variables are not explicit functions of time, the stability can be calculated and analyzed with the traditional root-locus methods [13]. The Eigenvalues are non-trivial solutions around an operating point calculated from

$$
A \Phi(t, t o)=\lambda \Phi(t, t o)
$$

where $A$ is the state matrix. If $A$ is real, the eigenvalues ( $\lambda$ ) always occur in conjugate pairs $\lambda=\sigma \pm j \omega$ where $\sigma$ is the damping coefficient and $\omega$ the angular speed of oscillation.

\section{ELECTRICAL MODELS}

\section{A. Load model}

The load model can represent static load components, such as resistive and lighting loads, but also approximate dynamic components [13]. The static characteristics of the load depend on the relationship between power and voltage. Load models for active and reactive power can be expressed in an exponential form

$$
\begin{aligned}
& P=P_{0} \times\left(V / V_{0}\right)^{k 1} \\
& Q=Q_{0} \times\left(V / V_{0}\right)^{k 2}
\end{aligned}
$$

where $P_{0}, Q_{0}$ and $V_{0}$ are the initial conditions of active, reactive power respectively, and voltage of the system and the coefficients define power $(k 1=k 2=0)$, current $(k 1=k 2=1)$ or impedance $(k 1=k 2=2)$. A constant power load model is considered in the study case presented in this article.

\section{B. Wind speed model}

Wind speed varies every minute, hour, day and season. If historical series of measurement of wind speed data are not available, it is necessary to consider a wind speed model. In this way, wind speed variation has been modeled by a Weibull Probability Density Function (PDF) [10], a composite wind speed model $[9,11]$ or a Mexican hat wavelet [4].

The wind speed model of Mexican hat wavelet allows evaluating critical variations of wind speed during a period of time. This deterministic wind gust model has been standardized by IEC [4] as the second derivative of the 
Gaussian distribution function, described by

$$
v_{w}(t)=v^{a}{ }_{w}+\left(v^{g}{ }_{w}-v^{a}{ }_{w}\right) \times\left(1-\frac{t-t_{0}}{\sigma^{2}}\right) \times e^{-\frac{\left(t-t_{0}\right)^{2}}{2 \sigma^{2}}}
$$

where $t_{0}$ is the centering time of the gust, $\sigma$ is the gust shape factor both in $\mathrm{s}, v^{g}{ }_{w}$ is the peak wind speed value, and $v^{a}{ }_{w}$ the average speed value both in $(\mathrm{m} / \mathrm{s})$.

\section{Wind power penetration}

It describes how the total installed wind power capacity in a certain region is related to the total peak load in this region over a period of time.

$$
\tau_{\text {Wind }}=\frac{\sum P_{\text {Wind }}}{\sum P_{L, \text { peak }}} 100 \%
$$

where $\tau_{\text {Wind }}$ is the wind capacity penetration, $P_{\text {Wind }}$ the installed wind power capacity and $P_{L, \text { peak }}$ the peak load.

\section{Stochastic Simulation}

The stochastic simulations are performed using Monte Carlo Simulation (MCS) method to evaluate the impact of load variation and identifying unstable scenarios. This method can be used in deterministic and stochastic problems. It is used in stochastic problems to create a complex estimation or forecasting situation that involves a high degree of uncertainty. Additionally, this method is used as reference for other probabilistic approaches. A load random sampling is performed during the dynamic simulation that determines the behavior of the network under a confidence measure for each value. Then, a mathematical model for the variable of uncertainty is needed, generally a probability function. The method forecasts the likely outcome of an event.

\section{A. Monte-Carlo Simulation}

The MCS uses the exact equations of the problem; it substitutes parameters of uncertainty for Random Variables (RVs) that follow a Probability Density Function (PDF) and performs a big number of deterministic analyses with the random trials. The results of the method are usually used as reference for other approaches. In order to get a high degree of accuracy, it requires a minimum of computations, which can be very time consuming. The relationship between the sample size and the estimate of the accuracy from a sample is given by

$$
e=\frac{z}{2 \sqrt{n}}
$$

where $n$ is the sample size, and e is the margin of error, by which the estimation may be incorrect. The variable $z$ is a function of how confident is the e estimation. Table 2 contains values of $z$ for some common confidence levels [14]:

Table 2: Values of $\mathrm{z}$ according to confidence level

\begin{tabular}{|c|c|c|c|}
\hline Confidence Level (\%) & 95 & 99 & 99.9 \\
\hline$z$ & 1.96 & 2.58 & 3.29 \\
\hline
\end{tabular}

The equation should not be used for $n \leq 30$, or probabilities that are extremely near zero or one unless a large number of samples are drawn.

\section{B. Probabilistic load model}

Load is very uncertain and difficult to model given its large number components, high distribution, variations with time of day and week, weather through time, and lack of information. Nevertheless, several Probabilistic Density Functions (PDFs) can be used to model power load behavior, for instance uniform, Weibull, normal, log-normal and beta [13]. A simplified model of load consumption is considered with an uniform distribution varying from lower $\left(P_{L m i n}\right)$ to upper $\left(P_{L \max }\right)$ values [13].

\section{Proposed method}

This procedure shows the steps to find the probability of instability of power network. Previously, it must be established power network parameters, configuration, wind power penetration, wind speed parameters $\left(t_{0}, \sigma\right)$, perturbation location at time $\left(t_{p}\right)$, number random trials $(n)$ of load variation at time $\left(t_{l}\right)$ and simulation time $\left(t_{f}\right)$. The following steps must be followed:

1. Initialize time domain simulation $\left(t_{i}=0\right)$ with a load flow.

2. Apply to time domain simulation load variation $\left(t_{l}\right)$, Mexican hat wavelet $\left(t_{0}\right)$, and perturbation $\left(t_{p}\right)$.

3 . Verify at every step of time $t$ that wind generation and network components restrictions are accomplished, otherwise disconnect them.

4. Complete time domain simulation, run at the end of simulation time $t=t_{f}$ a small-signal stability analysis.

5. Execute next time domain simulation and a small-signal stability analysis until $j>n$.

When MCS is completed it can be established a PDF of instability of the power network under a percentage of wind power penetration and consider the risk associated to its probability.

\section{STUdy CASE}

The study case is WECS network composed by 3-machine, 3-loads and 9-bus taken from [12]. This is ring topology in high voltage $230 \mathrm{kV}$, it is comparable to the power system of Guadalupe island. The original system was modified with the insertion of a wind farm at bus 06 . The network configuration is shown in figure 2 and the parameters are available in [12].

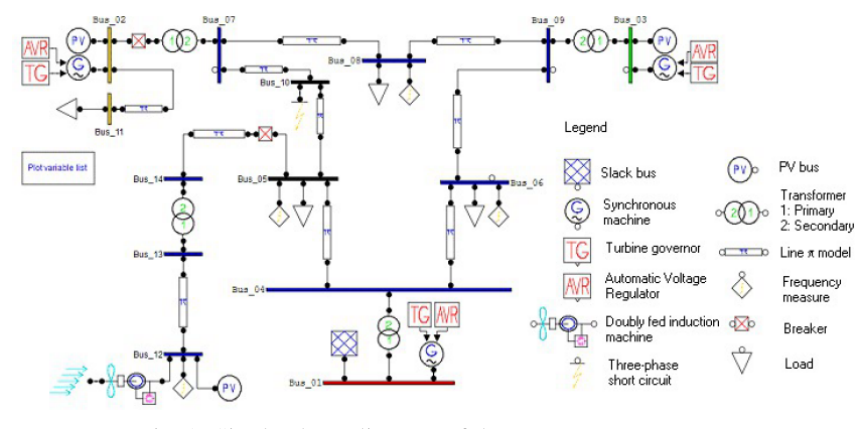

Fig. 2. Single phase diagram of three generators system.

The time domain simulation allows to study transient, 
voltage, and frequency stability, in order to determine the maximum wind capacity penetration $\left(\tau_{\text {Wind }}\right)$ connected to bus 6 . The wind capacity penetration is the ratio of the installed wind power capacity and the peak load. Stability criteria are: constant angle of rotor synchronous machines, voltage, and frequency permissible variations. Wind generation and component network constraints such as heat capacity of lines, maximum active, and reactive power of synchronous machines, must be respected.

Two severe contingencies are considered: three-phase short circuit and loss of a machine, under load and wind speed variations criterion $\mathrm{N}-1$. The disturbances are described below:

1. A three phase short-circuit occurs in the middle of the line of bus 05 and 07 at time $t_{p}=10$ s during $150 \mathrm{~ms}$ (about 8 cycles). The wind farm must be capable of withstanding the voltage dip during short-circuit to stay connected to the network.

2. The loss of synchronous machine of bus 02 occurs at time $t_{p}=30 \mathrm{~s}$. Meanwhile, the wind farm must support large voltage and frequency variations; otherwise, it must be disconnected (criterion $\mathrm{N}-2$ ).

The parameters of the models considered for wind speed Mexican hat wavelet are $t_{0}=15 \mathrm{~s}, \sigma=3 \mathrm{~s}, v^{a}{ }_{w} / v^{g}{ }_{w}=0.48$, while load variations follow an uniform distribution model of parameters $\left[P_{\text {Lmin }}, P_{\text {Lmax }}\right]=[0.95,1.05]$ p.u. which occur at time $t_{l}=5 \mathrm{~s}$.

\section{Results}

The case of three phase short-circuit with $\tau_{\text {Wind }}=43 \%$, did not represent a risk for network's stability under high wind power penetration; a stochastic analysis is not needed. The electrical variables such as bus voltages, frequency, active and reactive power were in the allowed range of values.

The case of loss of synchronous machine at bus 02 with $\tau_{\text {Wind }}=40 \%$ on the other hand, causes some unstable cases. The minimum frequency allowed to the wind farm is fixed to $48.5 \mathrm{~Hz}$. The frequency goes down, exceeding the minimum frequency allowed and causing the wind farm disconnection. The maximum active power of synchronous machine 03 and line 05-04 are close to reaching their limits (2 p.u.), which means that the capacity wind power penetration cannot be greater. In addition, the power system becomes oscillatory after the disconnection of the wind farm in some cases of MCS with a sample size of $n=50$. The results of bus frequency, voltages, machines active and reactive power are shown in figure 3.

Therefore, wind capacity penetration is decreased until all time domain simulations were stable after running MCS with a sample size of $n=50$. The maximum capacity wind power penetration without causing network oscillations, after the machine loss and the wind farm disconnection, is $\tau_{\text {Wind }}=$ $37 \%$. In the time interval during which the wind does not produce power (wind speed is zero) frequency drops below 49
Hz. As a consequence, the wind speed variation and low inertia of the wind farm may cause significant variations in frequency network, under disturbance or normal operating conditions. The network stable state is assured in front of the worst scenario of operation for this wind power penetration. The results of the electrical variables: synchronous machine frequencies, bus voltages, active and reactive power generated are shown in figure 4.

A small signal stability analysis is run at the end of time domain and MCS. In the case of $\tau_{\text {Wind }}=37 \%$ all poles are real and negatives, while $\tau_{\text {Wind }}=40 \%$ some of the closest poles to the imaginary axis become real and positive causing instability. The real positive values represent the oscillatory behavior of electrical variables. The results of Eigenvalue analysis are shown in figure 5.

The probability of network instability can be modeled using the results of eigenvalues analysis with a Bernoulli experiment [15]. The experiment models the probability of success or failure of the system to withstand disturbances, considering $\tau_{\text {Wind }}$ from $37 \%$ to $43 \%$. The number of success or failure corresponds to the number of unstable and stable cases at the end of the simulation time. The succession of independent Bernoulli experiments allows the construction of a variable counting the number of unstable cases (success), using a binomial distribution. The results of PDF and CDF are shown in figure 6 .
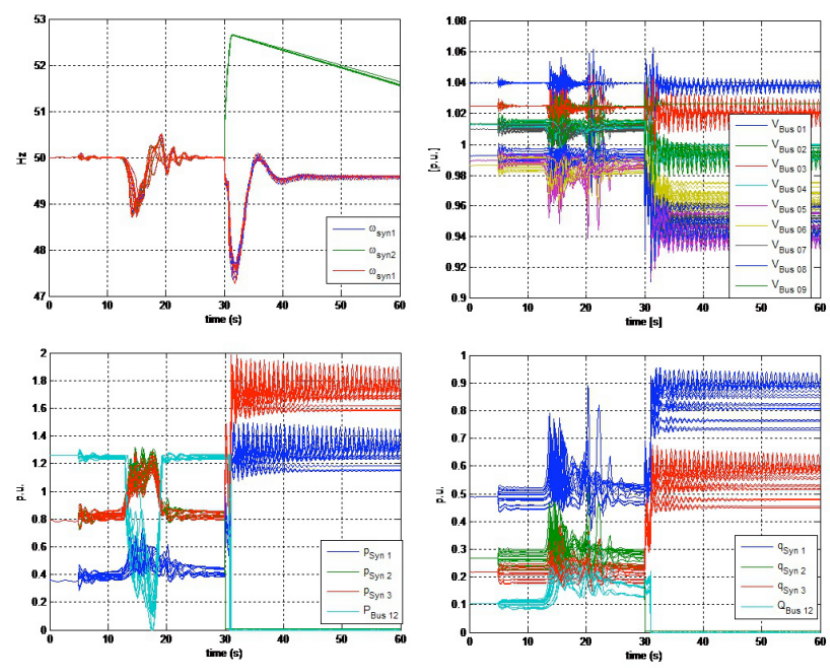

Fig. 3. Loss of synchronous machine at bus 02 with $\tau_{\text {Wind }}=40 \%$. 

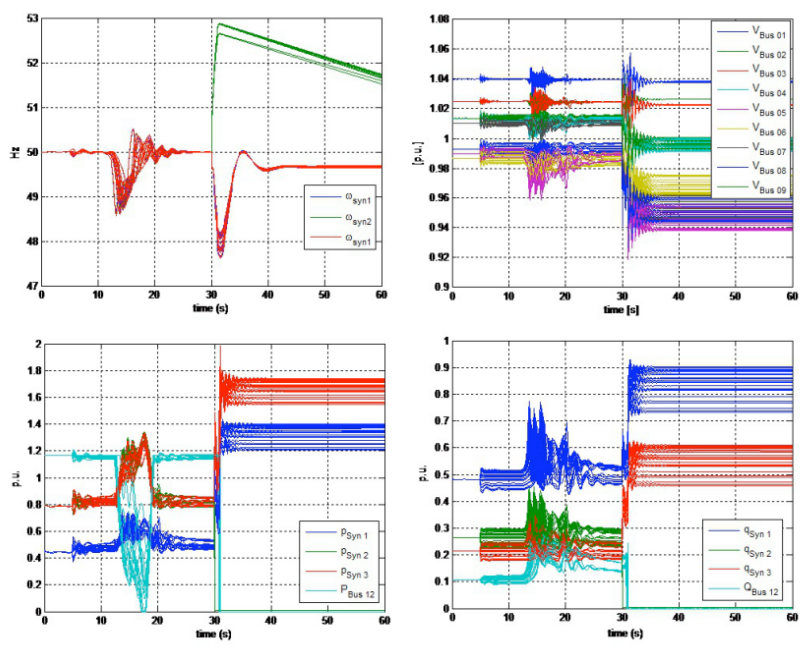

Fig. 4. Loss of synchronous machine at bus 02 with $\tau_{\text {Wind }}=37 \%$.
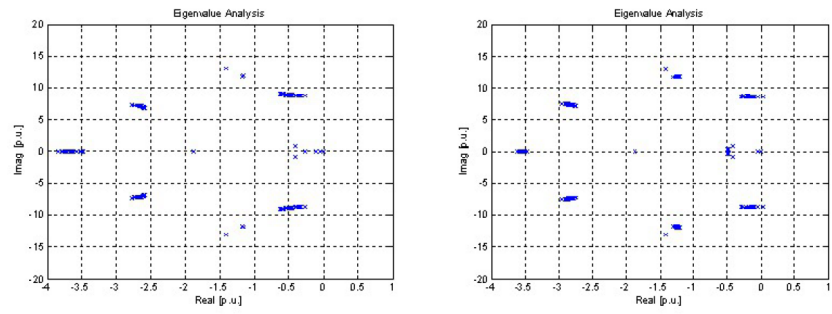

Figure 5: Eigenvalues for $\tau_{\text {Wind }}=37 \%$ and $\tau_{\text {Wind }}=40 \%$
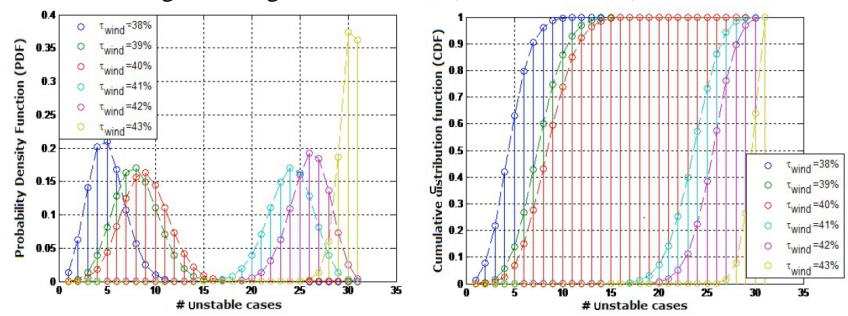

Figure 6: PDF and CDF of unstable cases.

The probability of instability (p) for the case $\tau_{\text {Wind }}=37 \%$ is zero; the system is always stable after MCS trials. As it can be seen in figure 6 , the PDF of instable cases with $\tau_{\text {Wind }}$ from $38 \%$ to $42 \%$ have the form of a discrete normal distribution, while for $\tau_{\text {Wind }}=43 \%$ the PDF is a discrete exponential. The wind power penetration increases the possibility of network instability, with it automatic disconnection of the network. The probability of instability of network according to $\tau_{\text {Wind }}$ can be found in table 3 .

TABLE 3: PROBABILITY OF UNSTABLE CASES

\begin{tabular}{|c|c|c|c|c|c|c|}
\hline$\tau_{\text {Wind }}(\%)$ & 38 & 39 & 40 & 41 & 42 & 43 \\
\hline $\mathrm{p}$ & 0.1613 & 0.1935 & 0.2258 & 0.7419 & 0.8065 & 0.9355 \\
\hline
\end{tabular}

\section{CONCLUSION}

In order to determine the maximum wind power penetration of an interconnected network, a new method was proposed. The proposed method is based on Monte-Carlo simulation considering load, an interval of wind speed variations applied to the case of machine loss, which represented the base case to determine maximum wind power penetration. Two scenarios of disturbances were examined, three-phase short-circuit and loss of a machine. The case of three-phase short-circuit was evaluated using a deterministic method, and it did not pose a risk to the stability of the network.

The time domain simulation and small signal stability were used to establish a probability density function of the network unstable cases. Constraints of synchronous machines, lines, and regulatory dynamic wind farms limitations of voltage, active power, reactive power and frequency taken from Irish grid code were considered.

The Eigenvalues at the end of simulation time were used to determine the probability of network instability. The loss machine criterion $\mathrm{N}-1$ risks the stability of the network by the disconnection of the wind farm, criterion $\mathrm{N}-2$. The Eigenvalues of the network were calculated for different percentages of wind power penetration $\tau_{\text {Wind }}$ from $37 \%$ to $43 \%$. Applying the proposed method with a wind power penetration of $37 \%$, electrical variables always return to steady state without violating network constraints and real part of Eigenvalues analysis were always negative. A binomial distribution models the network's unstable cases of wind power penetration above $37 \%$. The probability density function of unstable cases resembled a discrete normal distribution for the first cases of instability and to an exponential distribution for the last study case. The probability function allows associating a probability of instability or risk to a percentage of wind power penetration.

\section{REFERENCES}

[1] H. Moghimi, A. Ahmadi, J. Aghaei, A. Rabiee, Stochastic technoeconomic operation of power systems in the presence of distributed energy resources, International Journal of Electrical Power \& Energy Systems 45 (1) (2013) 477-488.

[2] W. Briceno Vicente, R. Caire, N. Hadjsaid, Interval arithmetic for shortcircuit computation in mv radial networks with distributed generation, in: Power and Energy Society General Meeting, 2012 IEEE, pp. 1 -6.

[3] E. Compatibility, Part 2-12: Environment compatibility levels for lowfrequency conducted disturbances and signaling in public medium-voltage power supply systems, Tech. rep., IEC 61000-2-12, Apr (2003).

[4] I. Standard, 61400-21, Measurement and Assessment of Power Quality of Grid Connected Wind Turbines.

[5] S. Bu, W. Du, H. Wang, Z. Chen, L. Xiao, H. Li, Probabilistic analysis of small-signal stability of large-scale power systems as a ff ected by penetration of wind generation, Power Systems, IEEE Transactions on 27 (2) (2012) 762-770.

[6] J. Rueda, I. Erlich, Impacts of large scale integration of wind power on power system small-signal stability, in: Electric Utility Deregulation and Restructuring and Power Technologies (DRPT), 2011 4th International Conference on, 2011, pp. 673-681

[7] E. Vittal, M. O'Malley, A. Keane, A steady-state voltage stability analysis of power systems with high penetrations of wind, Power Systems, IEEE Transactions on 25 (1) (2010) 433-442. 556.

[8] C. Zheng, M. Kezunovic, Impact of wind generation uncertainty on power system small disturbance voltage stability: A pcm-based approach, Electric Power Systems Research 84 (1) (2012) 10 - 19.

[9] H. R. Najafi, F. Dastyar, Dynamic maximum available power of fixedspeed wind turbine at islanding operation, International Journal of Electrical Power \& Energy Systems 47 (2013) 147-156.

[10] M. Matos, J. P. Lopes, M. Rosa, R. Ferreira, A. Leite da Silva, W. Sales, L. Resende, L. Manso, P. Cabral, M. Ferreira, et al., Probabilistic evaluation of reserve requirements of generating systems with renewable power sources: The portuguese and spanish cases, International Journal of Electrical Power \& Energy Systems 31 (9) (2009) 562-569. 
[11] I. E. Committee, et al., Iec 61400-1: Wind turbines part 1: Design requirements, International Electrotechnical Commission.

[12] F. Milano, Power system modelling, Power System Modelling and Scripting (2010) 3-17.

[13] P. Kundur, N. Balu, M. Lauby, Power system stability and control, Vol. 4, McGraw-hill New York, 1994.

[14] D. Ellard, P. Ellard, Sq course book (2003).

[15] C. Grinstead, J. Snell, Introduction to probability, American Mathematical Society, 1997.

\section{BIOGRAPHIES}

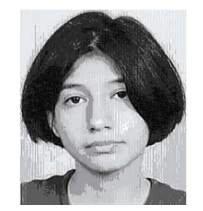

Wendy Carolina Briceño Vicente received her Electrical Engineer degree from Universidad Central de Venezuela (UCV), in 2006, Master and PhD degrees at the Grenoble Institute of Technology (Grenoble INP), France, in 2009 and 2012. Presently she works as design engineer at Siemens Wind Power A/S.

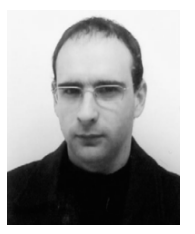

Raphael Caire (M’04) received his Diplômed'Etudes Approfondies (DEA) and Doctorat degrees from the Grenoble Institute of Technology (Grenoble INP) in 2000 and 2004. He is now associate professor at Grenoble Institute of Technology (Grenoble-INP). His research is centered on the impacts, production control of dispersed generation on distribution system and critical infrastructures.

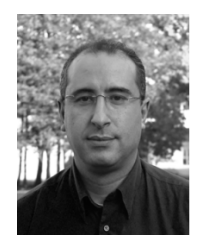

Nouredine Hadjsaid (SM'05) received his Diplôme d'Etudes Approfondies (DEA) and Doctorat degrees from the Grenoble Institute of Technology (Grenoble INP) in 1988 and 1992. He is full time professor at Grenoble INP. His research interests are power system operation and security. Since 1992, he has been involved as a scientific director for more than 20 industrial and European projects in the power energy sector and critical infrastructures. 